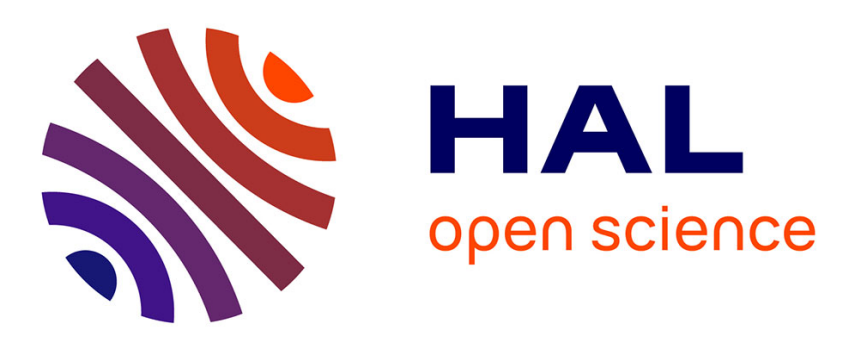

\title{
Janzen-Connell patterns are not the result of Janzen-Connell process: Oak recruitment in temperate forests
}

Maud Deniau, Vincent Jung, Cécile Le Lann, Thibault Morra, Phil J. Murray, Andreas Prinzing

\section{To cite this version:}

Maud Deniau, Vincent Jung, Cécile Le Lann, Thibault Morra, Phil J. Murray, et al.. Janzen-Connell patterns are not the result of Janzen-Connell process: Oak recruitment in temperate forests. Perspectives in Plant Ecology, Evolution and Systematics, 2017, 24, pp.72-79. 10.1016/j.ppees.2016.12.001 . hal-01483989

HAL Id: hal-01483989

https://hal-univ-rennes1.archives-ouvertes.fr/hal-01483989

Submitted on 11 Apr 2017

HAL is a multi-disciplinary open access archive for the deposit and dissemination of scientific research documents, whether they are published or not. The documents may come from teaching and research institutions in France or abroad, or from public or private research centers.
L'archive ouverte pluridisciplinaire HAL, est destinée au dépôt et à la diffusion de documents scientifiques de niveau recherche, publiés ou non, émanant des établissements d'enseignement et de recherche français ou étrangers, des laboratoires publics ou privés. 
Janzen-Connell patterns are not the result of Janzen-Connell process:

oak recruitment in temperate forests

Maud Deniau ${ }^{\mathrm{a} *}$, Vincent Junga ${ }^{\mathrm{a}}$ Cécile Le Lann, Thibault Morra ${ }^{\mathrm{a}}$, Phil J. Murray ${ }^{\mathrm{b}}$ and Andreas

Prinzing $^{\mathrm{a}}$

${ }^{a}$ University of Rennes 1, Centre National de la Recherche Scientifique, Research Unit UMR 6553

'Ecosystems, Biodiversity, Evolution', Campus Beaulieu, Bâtiment 14A, 263 Av. du Général Leclerc,

35042 Rennes cedex, France

${ }^{b}$ Sustainable Soils and Grassland Systems Department, Rothamsted Research, North Wyke,

Okehampton, Devon EX20 2SB, United-Kingdom

*Corresponding author. Email: maud.deniau@sfr.fr; fax number: +332 23235026 . 


\title{
Highlights
}

- Janzen-Connell suggests high enemy pressure on seedlings close to conspecific adults

- However, conspecific adults also improve the microenvironment for seedlings

- Heterospecific adults are refuge for seedlings, not conspecific adults a danger

- JC-like patterns may result from non-JC processes, with very different consequences

\begin{abstract}
According to the Janzen-Connell hypothesis, seedling mortality is greater close to conspecific (or closely related) adult trees because of higher enemy pressure, ultimately increasing local tree-species diversity. However, this pattern (i.e. a decline of seedling performance close to conspecific or closely related adults) could also result from other processes: (1) heterospecific adults might positively affect seedlings; (2) conspecific (or closely related) adults might negatively affect seedlings by causing a deterioration of the microenvironment. We tested these hypotheses, accounting also for sizes of adults. We planted oak-seedlings in a temperate forest, characterized their adult neighbourhoods, measured 26 microenvironmental conditions, seedling mortality during one year, budburst and leaf herbivory. We detected Janzen-Connell-like patterns (frequent lack of budburst close to conspecific adults; high seedling mortality close to closely related adults) that were consistent with the Janzen-Connell process. However, these patterns were either counteracted by non-Janzen-Connell processes such as a favourable microenvironment or were weak with little explained variance. We detected JanzenConnell-like patterns that were not consistent with the Janzen-Connell process: proximity to heterospecific adults per se decreased leaf herbivory partly due to microenvironmental effects, such that a lower leaf herbivory decreased seedling mortality. Overall, the spatial pattern of tree recruitment may resemble that predicted by Janzen-Connell but result from different processes: notably
\end{abstract}


heterospecific adults creating refuges from enemies, facilitating the establishment of oaks below nonoaks without hindering their establishment below oaks.

Keywords: budburst; community dynamics; intraspecific and interspecific facilitation; leaf herbivory; plant population; Quercus sp.

\section{Introduction}

A major challenge in community ecology is to understand mechanisms promoting species diversity in forests. Many mechanisms have been suggested (Wright, 2002), but the Janzen-Connell (JC) hypothesis (Connell, 1971; Janzen, 1970) remains widely used. According to the JC hypothesis, seedlings will suffer from proximity to conspecific adult trees (or closely related adults, see Liu et al., 2012) because of high pressure from specialized natural enemies. Seedlings of other species will thus be able to establish under the adult tree, thereby increasing species diversity of communities. The JC hypothesis has been confirmed multiple times in both tropical (e.g. Bagchi et al., 2014; Clark and Clark, 1984; Comita et al., 2014) and temperate forests (e.g. Comita et al., 2014; Masaki and Nakashizuka, 2002; Packer and Clay, 2000; Seiwa et al., 2008) but does not always hold true and is still debated (Hyatt et al., 2003). One aspect that has been largely overlooked is that a JC pattern (i.e. a decline of seedlings close to conspecific or closely related adults) might also result from other processes: (1) heterospecific adults might positively affect seedlings (rather than negative effect of conspecific or closely related adults), and (2) conspecific (or closely related) adults might negatively affect seedlings by causing a deterioration of the microenvironment (rather than by increasing enemy pressure)

A JC pattern may result from a reduced enemy pressure close to heterospecific adults, rather than from an increased enemy pressure close to conspecific adults. An adult tree is a reservoir of specialized enemies, aggregating nearby the adult tree (Connell, 1971; Janzen, 1970). Hence, a heterospecific adult attracts its own specialized enemies, which are not able to attack proximate focal seedlings due to a conservatism of biotic interactions (see Winkler and Mitter, 2008). Heterospecifics 
might even hinder the detection of focal seedlings by their enemies (Jactel et al., 2001). Heterospecific adults may thus represent a refuge for focal seedlings by decreasing enemy pressure, thereby improving seedling survival. Overall, a reduction of the enemy pressure close to heterospecific adults could be a non-JC process inducing a JC-like pattern, but with very different consequences: seedlings of focal species would establish below heterospecifics instead of heterospecifics below focal species (see also Rutten et al., 2016).

A JC pattern may also result from a deterioration of the microenvironment of seedlings by conspecific adults, or from an improvement of the microenvironment of seedlings by heterospecific adults. Adult trees might affect some or all of the following aspects of the microenvironment all influencing seedling survival; litter decomposition and chemistry, the physical structure of the microenvironment, and the microclimate and composition of the herbaceous layer. Moreover, the effect of adult trees on the microenvironment may be species-specific, resulting in a detrimental microenvironment under conspecific adult trees and in a beneficial microenvironment under heterospecific adult trees. This is often the case during ecological succession when a plant species improves the microenvironment for heterospecific seedlings and late-successional species profit from the microenvironments produced by early-successional species depending on repetitive disturbances. For instance, soil characteristics might differ between tree species due to the physical and chemical properties of their litter (Binkley, 1995). Different tree species might also differ in soil moisture because rain interception depends on species-specific tree characteristics (e.g. branch angle, bark type; Crockford and Richardson, 2000). Finally, evolutionary distant adult trees might have a very different impact on their microenvironment compared to the focal species. For example, Gymnosperms produce less litterfall than Angiosperms, and also a more acidic litter hence resulting in a lower soil $\mathrm{pH}$ (Sariyildiz et al., 2005). The stemflow is also very low for Gymnosperms (Crockford and Richardson, 2000). If the impact of adult trees on their proximate microenvironment changed gradually with evolutionary position, the resulting effect on seedling survival may be more similar between a conspecific adult and a closely related than a distantly related adult. Overall, a deterioration of the microenvironment by conspecific (or closely related) adults, and an improvement of the 
microenvironment by heterospecific (or distantly related) adults could both be non-JC processes inducing a JC pattern.

The impact of a tree on proximate seedlings might be reinforced with the size of that tree. Larger adult trees have a larger crown and a larger root system, so they could accumulate more specialized enemies than smaller adults (see Packer and Clay, 2000, referring to Janzen, 1970). Moreover, larger adult trees are mostly older and have affected their microenvironment for a longer period, intensifying their specific microenvironmental conditions. Also, the impact of a large adult tree on proximate seedlings potentially extends over a greater spatial distance. Size may even impact seedlings more strongly than distance does. Overall, the visibility of a JC pattern might be reinforced with the size of the tree (see Packer and Clay, 2000, referring to Janzen, 1970), regardless of the process involved: the negative effect of a large conspecific adult may increase with the size of that tree, just as the positive effect of a heterospecific adult.

We tested the above hypotheses on alternative processes inducing a JC pattern, using oaks (Quercus) as study model, in a temperate forest. Natural regeneration of temperate forests is usually described as depending on light and thus on the creation of canopy gaps (about gap theory, see Yamamoto, 1992). Creation of canopy gaps induces a gradient of light quality and hence of regeneration niches. Some of those niches will correspond to the high-light requirement of temperate oak trees, known to be relatively shade-intolerant (Ellenberg et al., 1992). We studied seedlings because it is at this stage that the JC signal has been described to be the strongest (Comita et al., 2014; Connell, 1971; Hyatt et al., 2003). We planted oak seedlings as phytometers in order to avoid bias due to local acclimatization or selection. We measured seedling mortality and processes controlling seedling mortality (budburst and leaf herbivory). Mortality decreases with physiological performance, and a core characteristic of performance in seedlings is budburst and particularly an early budburst (Augspurger, 2008; Besford et al., 1996; Seiwa, 1998), allowing photosynthesis and nutrient acquirement during the best light conditions, before the closure of the canopy. Mortality of seedlings also increases with leaf herbivory (Moles and Westoby, 2004; Wada et al., 2000) by removing photosynthetic tissues. Even low levels of herbivory may strongly increase seedling mortality given 
their small overall leaf area. Firstly, we tested the classical prediction of JC hypothesis, i.e. that proximity to conspecific adult tree increases seedling mortality, lack and delay of budburst and leaf herbivory. Secondly, we expanded the classical JC hypothesis to other aspects of adult neighbourhood by testing whether heterospecifics or distant relatives decrease seedling mortality, lack and delay of budburst and leaf herbivory, and whether size of trees reinforces the effect of distance or exerts an independent effect. Thirdly, we opened JC hypothesis to the microenvironment. We tested if adults affect litter decomposition and chemistry, physical structure of microenvironment, microclimate and composition of herbaceous layer, in order to estimate if previously identified effects of neighbourhood on seedlings are directly determined by the neighbourhood (potentially due to enemy pressure) or mediated by the microenvironment.

\section{Material and methods}

\section{SITE DESCRIPTION}

The study was conducted between 2013 and 2015 in the Forest of Rennes, Brittany, France $\left(48^{\circ} 12^{\prime} \mathrm{N}, 1^{\circ} 33^{\prime} \mathrm{W}\right.$, ca. $90 \mathrm{~m}$ altitude), a semi-natural managed forest with oceanic climate, mean annual temperature of $11.3^{\circ} \mathrm{C}$ and cumulated annual rainfall of $836 \mathrm{~mm}$. The soil is a brown-leached soil. This forest is composed of two parcel types dominated by either oak (Quercus petraea hybridizing with Quercus robur) and beech (Fagus sylvatica) or Scots pine (Pinus sylvestris) interspersed with other Angiosperms. The other main tree species in the overstorey are typical from European temperate oceanic lowland forests: Ilex aquifolium, Castanea sativa, Sorbus torminalis, Abies alba and Carpinus betulus (see Yguel et al., 2011 for further details). The herbaceous layer contained seedlings of different tree species: Quercus spp., F. sylvatica, C. sativa, I. aquifolium, A. alba, P. sylvestris; ferns predominantly Pteridium aquilinum; grasses mainly Molinia caerulea; other Angiosperms such as Rubus spp., Hedera helix, Lonicera periclymenum, and bryophytes.

Ten pairs of two adult oak-trees (ca. 60 years old) were selected within the forest (used by Yguel et al., 2011). Each pair had one tree in the more oak-dominated parcel and one in the more pinedominated parcel, separated by distances of less than $150 \mathrm{~m}$. Selecting adult oak-trees in both types of 
parcels ensured a large range of evolutionary distance between seedlings and their adult neighbours. Trees of the same pair were of the same oak species (Q. petraea or Q. robur, not strictly speaking distinct species are always partly hybridized; Yguel personal communication). This blocked design was essential to control for variation among pairs due to different macroenvironments or different sources of seedlings (Legendre et al., 2004), we thus used 'tree pair' as random factor in further analyses.

\section{EXPERIMENTAL DESIGN}

For each of the ten pairs, twenty oak-seedlings (Q. petraea or Q. robur or hybrids) were harvested in January 2013 around the adult oak-tree located in the more oak-dominated parcel (seedlings were too rare in the more pine-dominated parcel). Seedlings were carefully chosen in order to be approximately of the same height/age (ca. 1 year old), morphology, no longer dependent upon stored seed reserves (no acorn attached), have no visible signs of pathologies or damage, and have intact buds. Seedlings were then immediately planted along a $5 \mathrm{~m}$ transect perpendicular to the stem of each focal adult oak, with seedlings planted every $50 \mathrm{~cm}$ (Fig. 1). A transect length of $5 \mathrm{~m}$ ensured that the focal oak was usually the closest conspecific while ensuring also sufficient variation in distance.

\section{CHARACTERIZATION OF ADULT NEIGHBOURS}

As we worked inside a forest, each transect of seedlings was surrounded by adult trees other than the focal adult oak, most of which being heterospecifics (Fig. 1). For each seedling, we determined the spatial distance to the stem position of the closest conspecific and of the closest heterospecific adult tree (> $2 \mathrm{~m}$ height), hereafter respectively referred as 'conspecific' and 'heterospecific'. Distance to conspecific adult ranges from $0.3 \mathrm{~m}$ to $5.0 \mathrm{~m}$ (mean $2.5 \pm 1.3 \mathrm{~m}$ ) and distance to heterospecific adult ranges from $0.2 \mathrm{~m}$ to $6.8 \mathrm{~m}$ (mean $2.4 \pm 1.4 \mathrm{~m}$ ). Note that distance to conspecific and distance to heterospecific adults are not correlated $(-0.023 ; \mathrm{P}=0.74$, d.f. $=198)$. Hence, a seedling which is distant to a conspecific adult is not necessarily close to a heterospecific adult. A seedling can thus be close (or distant) to both conspecific and heterospecific adults. As a proxy of tree size we measured circumference at breast height, which is also related to crown size. When two adult 
trees were equally close, the average distance and circumference ('size' from hereon) was taken. The evolutionary distance between each focal seedling and the spatially closest adult tree was also quantified (see Appendix A for explanation of the procedure). Again, when two trees were equally close to a seedling, the respective mean evolutionary distance was calculated. Evolutionary distance varies continuously from 0 to 140 million year before present.

\section{MEASUREMENTS OF SEEDLING MORTALITY, BUDBURST AND LEAF HERBIVORY}

'Seedling mortality' was quantified for the second year only (2014), because we expected that for the first year part of the mortality was due to transplantation. We hence excluded seedlings which died in the first year from analyses. We described seedlings as 'dead' or 'alive'. The cause of the death was not assessed as we were interested in explaining the overall seedling mortality by the microenvironment, without distinction. Seedlings were considered as dead when they were dry and brittle or unearthed or broken at the base (the latter two often occurring due to the seedlings being dry and brittle before).

'Lack of budburst' and 'budburst delay' were estimated in the second year (2014) only to avoid bias due to transplantation, with the survey beginning in February when all seedlings had closed buds, and ceasing in late June when most of the seedlings had burst. We assessed the 'lack of budburst' by noting whether seedlings had burst (i.e. developed a fully-opened bud with leaves) or not during the season of survey. The 'budburst delay' was assessed by following the phenology: seedlings were screened for a fully-opened bud every 3 days until the end of May and approximately every week until the end of June. Day zero of budburst delay was defined as the day the first seedling had burst (5 March 2014, note that buds of adults burst later). Budburst delay was then calculated as the number of days from day zero necessary for a seedling to develop a fully-opened bud. Only seedlings that had burst during the survey (between February and late June) were accounted for in the budburst delay variable.

'Leaf herbivory' was estimated in the second year (2014), with survey starting when the leaves from the first bud had burst (5 March 2014) and ceasing in late September, when most of the leave 
damages have occurred (Wada et al., 2000). Herbivores were mainly Lepidopteran larvae, the major cause of oak defoliation in temperate forests (Southwood et al., 2004), most of them being monophagous or oligophagous (see Yguel et al., 2011 for a list of the Lepidoptera species found on the focal adult oaks). The number of leaves per seedling was recorded every 3 days until the end of May, and once per month from thereon until September. Such a high temporal resolution of the screening allowed us to identify cases where an entire leaf had been consumed. In late September, the leaf area loss on the remaining leaves of each seedling was visually estimated by the same observer. For each seedling, total 'leaf herbivory' hence included the leaf area loss on the remaining leaves and the number of leaves totally consumed during the season, following the formula: \% leaf herbivory= $100 *$ (number of leaves totally consumed $+($ number of remaining leaves * proportion of area consumed from these remaining leaves)) / (number of leaves totally consumed + number of remaining leaves).

\section{MEASUREMENTS OF THE MICROENVIRONMENT}

Methodology and justifications of these measurements are given in Appendix B. In short, 26 parameters were studied in the proximity of each seedling: litter decomposition and chemistry, physical structure of the microenvironment, microclimatic conditions and composition of the herbaceous layer: thicknesses of Oi and Oe horizon; decay of oak-leaves and of a standard substrate (cellulose); soil $\mathrm{pH}$; carbon/nitrogen $(\mathrm{C} / \mathrm{N})$ ratio in the Oa horizon where seedlings root. The presence of major roots, fine roots, stones and dead wood close to each seedling was characterized, and the relative elevation of the litter surface was determined. Soil temperature and moisture and the percent of canopy openness were measured just before budburst of seedlings. Finally, vegetation cover was assessed around each seedling. Microenvironmental parameters were measured at the beginning of the growing season. Soil temperature and moisture were recorded in the second year (the year of the survey of seedling mortality, budburst and leaf herbivory), as they might vary from year to year. The other remaining parameters are more structural and compositional and less variable and were hence only measured in year 1 . 


\section{DATA ANALYSIS}

All statistical analyses were performed using R version 3.1.1 (R Core Team, 2014) and the following packages: lme4 (Bates et al., 2015), MuMIn (Barton, 2015), nlme (Pinheiro et al., 2014), piecewiseSEM (Lefcheck, 2016), RVAideMemoire (Hervé, 2015). We checked for multicollinearity among variables that would be predictive (i.e. among variables characterizing adult neighbours and among variables characterizing the microenvironment), inferred from strong correlations ( $>$ unsigned 0.7) among variables, and found none. The experimental design used blocks, thus mixed models were always utilized, with 'tree pair' as random factor. Generalized Linear Mixed Models (GLMMs) were utilized for explaining binomial variables (seedling mortality and lack of budburst) with the binomial error distribution and a logit link function; Linear Mixed Models (LMMs) were utilized for explaining budburst delay and leaf herbivory. The adequacy of the model to data was always checked graphically with residuals-vs-fitted values plot and QQ-plot of the residuals.

We tested the effect of lack of budburst, budburst delay and leaf herbivory on seedling mortality with GLMMs. Budburst delay affected seedling mortality only slightly $(\mathrm{z}=1.68, \mathrm{P}=0.094$, $\mathrm{R}^{2} \mathrm{~m}=0.039, \mathrm{R}^{2} \mathrm{c}=0.039, \mathrm{n}=93$ ), and was hence not considered in the following analyses.

First, seedling mortality, lack of budburst and leaf herbivory were explained by distance to the closest conspecific alone, testing for a classical JC pattern. Variance explained by each model was estimated by calculating the marginal $\mathrm{R}^{2}$ (i.e. variance explained by fixed factors only) and the conditional $\mathrm{R}^{2}$ (i.e. variance explained by both fixed and random factors) (Nakagawa and Schielzeth, 2013).

Secondly, seedling mortality, lack of budburst and leaf herbivory were each explained by all characteristics of the adult neighbourhood included in a single mixed model: distance and size of closest conspecific and closest heterospecific, the corresponding distance:size terms, and evolutionary distance to closest adult, using GLMMs or LMMs as explained above. In order to reduce the number of predictor variables, we conducted best subset research. The best selected model was the one with the lowest corrected Akaike Information Criterion (AICc; Hurvich and Tsai, 1989). AICc is recommended instead of $\mathrm{AIC}$ when $\mathrm{n}($ sample size $) / \mathrm{k}$ (estimated parameters) $<40$ (Burnham and 
Anderson, 2002). We verified that conditional $\mathrm{R}^{2}$ of the selected model was close to that of the full model containing all independent variables and hence variable selection was unambiguous and did not result in a major loss of information.

Finally, we evaluated whether the effects of neighbouring adults on seedling mortality, or processes controlling seedling mortality (lack of budburst and leaf herbivory) were direct or indirect through the influence of the neighbourhood on the microenvironments. For this purpose, we used piecewise SEM (Structural Equation Modelling) as it allows the use of mixed models and thus the random factor 'tree pair'. We built our piecewise SEM on the linear mixed models explained above and included all neighbourhood variables that significantly influenced either seedling mortality, lack of budburst or leaf herbivory. In a first approach we included all microenvironmental variables significantly influenced by any of the retained neighbourhood variables (in separate regression analyses, see Appendix C). However, such a model contained a high number of variables (29) for the sample size $(\mathrm{n}=93)$, and the fit statistics revealed that the resulting model was not acceptable (Fisher's $C$ statistic, $\mathrm{P}<0.05)$. We thus proceeded with a stricter selection among microenvironmental variables, including only those significantly influencing seedlings (either their mortality, lack of budburst or leaf herbivory). This selection was conducted with mixed models including 'tree pair' as random factor, and the best model was selected according to AICc (see Appendix D for details). A piecewise SEM based on these variables still yielded a bad fit of the model (Fisher's $C$ statistic, $\mathrm{P}<0.05$ ), suggesting that important paths were missing. We added those 4 missing paths (detailed in Appendix E) and obtained a good overall fit of the model (Fisher's $C$ statistic, $\mathrm{P}>0.05$ ): no paths were missing and the model represented the data well. We refrained from calculating compound paths as some of the underlying models had non-normal error distributions, rendering the precise estimates of parameters incompatible among models.

\section{Results}

We observed major variations in budburst delay (from 0 to 106 days, average 48 days) and leaf herbivory (from 0 to $100 \%$, average $60 \%$ ). Mortality was $64.7 \%$ (117/181), after exclusion of the 19 seedlings which died in year one. 
Seedling budburst (lack and delay) and leaf herbivory were hypothesized to be processes controlling seedling mortality. Seedling mortality was increased by a lack of budburst $(z=5.98, P<$ $\left.0.001, \mathrm{R}^{2} \mathrm{~m}=0.33, \mathrm{R}^{2} \mathrm{c}=0.36, \mathrm{n}=181\right)$ and by a delayed budburst $\left(\mathrm{z}=1.68, \mathrm{P}=0.094, \mathrm{R}^{2} \mathrm{~m}=0.039\right.$, $\mathrm{R}^{2} \mathrm{c}=0.039, \mathrm{n}=93$ ). Lack of budburst was much more strictly related to mortality than budburst delay and so we kept lack of budburst only in the analyses. Seedling mortality was increased by a high leaf herbivory $\left(\mathrm{z}=3.02, \mathrm{P}=0.0026, \mathrm{R}^{2} \mathrm{~m}=0.13, \mathrm{R}^{2} \mathrm{c}=0.13, \mathrm{n}=97\right)$. Lacking budburst and leaf herbivory are thus processes that contribute to seedling mortality.

\section{WAS THERE A CLASSICAL JANZEN-CONNELL PATTERN?}

Proximity to conspecific adult did not influence the mortality of seedlings $(z=1.10, P=0.27$, $\left.\mathrm{R}^{2} \mathrm{~m}=0.0091, \mathrm{R}^{2} \mathrm{c}=0.044, \mathrm{n}=181\right)$.

Proximity to conspecific adult influenced one of the processes controlling seedling mortality: seedling budburst lacked at proximity of the conspecific adult $\left(\mathrm{z}=2.10, \mathrm{P}=0.036, \mathrm{R}^{2} \mathrm{~m}=0.031, \mathrm{R}^{2} \mathrm{c}=\right.$ $0.049, \mathrm{n}=181)$. However, proximity to conspecific adult did not influence the leaf herbivory $(\mathrm{t}=0.67$, $\left.\mathrm{P}=0.50, \mathrm{R}^{2} \mathrm{~m}=0.0044, \mathrm{R}^{2} \mathrm{c}=0.11, \mathrm{n}=97\right)$.

\section{DID NEIGHBOURING ADULTS INFLUENCE SEEDLING MORTALITY, LACK OF}

\section{BUDBURST AND LEAF HERBIVORY?}

Accounting for all five variables characterizing adult neighbourhoods allowed us to detect a distinct relationship between neighbourhood and mortality, lack of budburst and leaf herbivory (Table 1): proximity to conspecific adults, again, increased lack of budburst, whatever the size of conspecific adults. Proximity to heterospecific adults decreased leaf herbivory on seedlings, whatever the size of heterospecifics. Finally, having an evolutionary proximate neighbour tended to increase seedling mortality.

WERE EFFECTS OF NEIGHBOURING ADULTS ON SEEDLINGS DIRECT OR MEDIATED BY THE MICROENVIRONMENT? 
Proximity to conspecific adult indirectly promoted budburst where there was a lower $M$. caerulea cover (Fig. 2). We note that the proportion of explained variance for lack of budburst was distinctly increased when considering microenvironment (Table 1 vs. Fig. 2), and that lack of budburst no longer affected seedling mortality.

Proximity to heterospecific adult decreased directly leaf herbivory (Fig. 2), and indirectly through a lower number of $F$. sylvatica seedlings. Moreover, a low level of leaf herbivory reduced seedling mortality. Proximity to heterospecifics also tended to inhibit budburst through a high $M$. caerulea cover.

Finally, the evolutionary proximity with the closest adult no longer affected seedling mortality (directly or indirectly), when considering microenvironmental and neighbouring variables (Table 1 vs Fig. 2). 


\section{Discussion}

In our study system using a simple regression analysis, we did not detect a classical JC pattern, i.e. negative effects of proximate adults on seedlings. However, once we accounted for heterospecifics and evolutionary distances (Table 2) we did detect multiple JC-like patterns. Some of these JC-like patterns (frequent lack of budburst close to conspecifics; high seedling mortality close to closely related adults) were consistent with the JC process (i.e. negative effect of proximity to conspecific or closely related adult) but could be respectively counteracted by a favourable microenvironment or weak with little explained variance. Other JC-like patterns were due to non-JC processes, such as heterospecific adults reducing leaf herbivory and hence decreasing mortality of proximate seedlings. Specifically, reduced leaf herbivory close to heterospecifics was partially explained by a beneficial microenvironment. To our knowledge, this is the most comprehensive characterization of processes that potentially can induce a JC pattern, and the first observation that JC-like patterns could result from processes other than a direct negative effect of the conspecific (or closely related) adult (but see Rutten et al., 2016). This study demonstrates that JC patterns are mostly the result of non-JC processes, and that the JC process did not result in distinct JC patterns. Spatial pattern of tree recruitment could result from mechanisms other than the one suggested by JC: heterospecific adults constitute refuge from enemies, and these refuges may in some cases be close to conspecifics as distances to con- and heterospecifics are uncorrelated. The result would be establishment of oaks below non-oaks and ultimately a decrease of beta diversity between adult neighbourhoods rather than an increase alpha diversity within.

\section{LIMITATIONS OF OUR STUDY}

Our study clearly has limitations, including the ontogenetic stage and time window. First, we found no evidence for classical JC process on the seedling stage, but we cannot exclude that JC process act on other stages (e.g. seeds), as we studied only seedlings. However, a stronger JC process on seeds rather than on seedlings seems unlikely as the study of Connell (1971) and the meta-analyses of Comita et al. (2014) and Hyatt et al. (2003) have found the strongest JC effects on the seedling stage. Second, our study was conducted on a limited window of time (2 years). We cannot exclude that 
the JC process become detectable after many years of pressure by enemies. In fact, the mortality in year 2 (excluding seedlings which possibly die from transplantation) was $64.7 \%$, which suggests that many seedlings are still to die as not all those remaining seedlings could become adults. At the same time, the number indicates that what we observed during this 2-year time window is far from irrelevant.

\section{JANZEN-CONNELL PATTERNS RESULTING FROM THE JANZEN-CONNELL PROCESS EXIST BUT TEND TO BE WEAK OR OVERLAID BY THE MICROENVIRONMENT}

Consistent with a JC pattern, seedlings were negatively affected by proximity to conspecific adult through a reduction of their budburst (Table 1). This result is consistent with Packer and Clay (2003) showing that proximity to conspecific adults not only affects mortality but also reduces seedling growth. Whilst we found no effect of distance to conspecific adult on leaf herbivory, soil pathogens could be implicated. Packer and Clay (2003) showed that soil pathogens explained the reduced growth of seedlings proximate to a conspecific adult. It has also been shown that some soil pathogens have a detrimental effect on seedling budburst (e.g. Taylor and Wallace, 1970), hence potentially explaining the reduced budburst of seedlings with proximity of a conspecific adult. However, we note that the result disappears after accounting for microenvironmental conditions. Microenvironment overlays (rather than explains) the negative direct effect of conspecific adults, and hence counters the JC process, i.e. pressure by natural enemies: conspecific adults created a favourable microenvironment by reducing $M$. caerulea cover at their proximity, thus enhancing seedling budburst. M. caerulea could reduce seedling physiological performance because it is an efficient competitor of tree seedlings (Balandier et al., 2006) by developing a dense root system and forming very dense tufts (Taylor et al., 2001). Conspecific adults might hence both exert JC effects and mask them by creating a favourable microenvironment that counters the direct negative effect of the conspecific adult, potentially explaining why the JC pattern has not always been detected.

Consistent with a phylogenetic JC pattern (Liu et al., 2012), seedling mortality was increased by closely related adults (or decreased by distantly related adults), but this effect remains weak (Table 1). This relationship is consistent with other studies showing an increased survival of seedlings close 
to distantly related neighbours (Paine et al., 2012; Webb et al., 2006). Whilst we did not find evolutionary close relatives to increase leaf herbivory, there might be an increased pressure by soil pathogens (Liu et al., 2012): closely related neighbours might increase the risk for the focal seedling to encounter enemies, because many enemies feed only on a set of closely related host-tree species (Gossner et al., 2009). However, the inclusion of microenvironmental variables and others descriptors makes the negative effect of closely related adults disappear (Fig. 2), suggesting that the effect of evolutionary proximity on seedlings is weak or, again, mediated by the microenvironment or by a specific combination of con- and heterospecifics rather than an impact of close relatedness. We also note that, in the case of evolutionary proximity, we cannot distinguish between a negative effect of proximity and a positive effect of distance. Overall, a closely related adult has a weak negative effect on seedlings (or a distantly related adult a positive one), consistent with both phylogenetic JC pattern and process, but evolutionary proximity is far from being the major determinant of seedling recruitment.

\section{JANZEN-CONNELL PATTERNS RESULT FROM NON-JANZEN-CONNELL PROCESSES}

Consistent with a JC pattern, seedlings were positively affected by proximity to heterospecific adults through a lowered leaf herbivory, which reduced seedling mortality (Table 1; Fig. 2). However, the JC process would predict negative effect of proximate conspecific adults; heterospecific adults per se improving seedling recruitment is not considered in the classical JC process. Consistently with our results, some studies have shown an increased survival of seedlings with increasing heterospecific density (Comita and Hubbell, 2009; Peters, 2003) and an increased survival beneath the crown of heterospecifics compared to conspecifics (Zywiec, 2013). This JC pattern, due to beneficial effect of heterospecific adults rather than negative effect of conspecifics, is explained by enemies: we found that proximity to heterospecific adults reduce leaf herbivory (Table 1; Fig. 2). Positive effects of heterospecifics on seedlings support the species herd protection hypothesis (Peters, 2003; Wills and Green, 1995), which is an extension of the classical JC hypothesis. According to the herd protection hypothesis, increased heterospecific density will be beneficial for seedling survival because it reduces the risk of encountering species-specific enemies. Among others, odors from heterospecific adults 
might mask the odors from oak-seedlings and thereby reduce their detectability for enemies (e.g. Jactel et al., 2001). Here, we go further by demonstrating that proximity to a single heterospecific is beneficial, so that each heterospecific adult acts as a refuge for seedlings. We recall that the seedling is a potential future competitor of the heterospecific adult and that adults, by providing refuges that favour heterospecifics, to some degree prepare their own competitive replacement. Moreover, we found support for a mediation of this JC pattern by the microenvironment (Fig. 2): heterospecific adults reduced leaf herbivory on proximate seedlings, partly due to a lower density of $F$. sylvatica seedlings. Quercus and Fagus are evolutionary related genera and thus share many enemies (Gossner et al., 2009); a high density of $F$. sylvatica seedlings may hence contribute to attract enemies of oak seedlings. Overall, we detected a JC pattern due to a non-JC process, the support by heterospecific adults and this support operates via protection from enemies, partly due to a beneficial microenvironment.

\section{SIZE OF ADULT TREES DOES NOT REINFORCE JANZEN-CONNELL PATTERNS}

We found no support for stronger JC patterns with increasing size of adults (Table 1). Size per se of conspecific adult was not considered in the classical JC but was suggested to interact with distance by intensifying the JC pattern (see Packer and Clay, 2000, referring to Janzen, 1970). Here, we found no effect of size per se controlling seedling recruitment (mortality, lack of budburst and leaf herbivory), independently or in interaction with distance. Larger trees do not appear to accumulate more enemies than younger ones, nor to intensify their specific microenvironmental conditions.

Overall, within the ontogenetic time window we studied, the impact of a tree on proximate seedlings is not reinforced with the size of that tree.

\section{IMPLICATIONS FOR FOREST MANAGEMENT}

Oaks are a major source of quality wood, but regeneration is increasingly difficult in Europe (Humphrey and Swaine, 1997; Thomas et al., 2002). First, we demonstrated that seedling survival and processes driving seedling survival are mostly depending on neighbours other than conspecifics. In particular, heterospecifics constitute an efficient refuge for oak seedlings by reducing leaf herbivory 
and hence increasing their survival. In order to facilitate oak regeneration at the seedling stage, foresters may thus ensure to maintain species diversity in forest stands, as heterospecifics can directly improve seedling survival and reduce leaf herbivory. Second, we also detected a negative effect of cover by M. caerulea on seedling performance. An expansion of this grass species could be detrimental to the natural regeneration of understory species, including oak seedlings. Foresters may thus ensure to control this species by limiting its spread.

\section{Conclusions}

JC patterns were not produced by the JC process: they were the result of heterospecifics rather than conspecifics, and they were the result of both the microenvironment and enemies. In other cases, microenvironment-mediated processes partly countered the JC process. At least in our study system, heterospecifics are the most important predictor of seedling survival by exerting strong positive effects. These effects facilitate the establishment of oaks below non-oaks without hindering their establishment below oaks, hence contributing to ecological succession. Our results suggest that diversity in forests might be maintained not because proximity to conspecific is very unfavourable but because proximity to heterospecifics is particularly beneficial.

\section{Acknowledgements}

We thank Valérie Gouesbet and Stéphanie Llopis from Ecolex for their help on data collection, and the Office National des Forêts for logistic support. We also thank Guillaume Bouger for the preparation of the measuring equipment. We are grateful to Jonathan S. Lefcheck for his helpful advice about piecewise SEM. 


\section{References}

Augspurger, C.K., 2008. Early spring leaf out enhances growth and survival of saplings in a temperate deciduous forest. Oecologia 156, 281-286.

Bagchi, R., Gallery, R.E., Gripenberg, S., Gurr, S.J., Narayan, L., Addis, C.E., Freckleton, R.P., Lewis, O.T., 2014. Pathogens and insect herbivores drive rainforest plant diversity and composition. Nature 506, 85-88.

Balandier, P., Collet, C., Miller, J.H., Reynolds, P.E., Zedaker, S.M., 2006. Designing forest vegetation management strategies based on the mechanisms and dynamics of crop tree competition by neighbouring vegetation. Forestry 79, 3-27.

Barton, K., 2015. MuMIn: Multi-Model Inference. R Package version 1.15.1. http://CRAN.Rproject.org/package=MuMIn/ (accessed 30.10.15).

Bates, D., Maechler, M., Bolker, B., Walker, S., 2015. Fitting linear mixed-effects models using lme4. J. Stat. Softw. 67, 1-48.

Besford, R.T., Hand, P., Richardson, C.M., Peppitt, S.D., 1996. Photoperiod effect on bud burst in Prunus is phase dependent: significance for early photosynthetic development. Tree Physiol. 16, 491496.

Binkley, D., 1995. The influence of tree species on forest soils: processes and patterns, in: Mead, D.J., Cornforth, I.S. (Eds.), Proceedings of the Trees and Soils Workshop. Lincoln University Press, Canterbury, pp. 1-33.

Burnham, K.P., Anderson, D.R., 2002. Model selection and multimodel inference: a practical information-theoretic approach, second ed. Springer, New-York.

Clark, D.A., Clark, D.B., 1984. Spacing dynamics of a tropical rain forest tree: evaluation of the Janzen-Connell model. Am. Nat. 124, 769-788.

Comita, L.S., Hubbell, S.P., 2009. Local neighbourhood and species's shade tolerance influence survival in a diverse seedling bank. Ecology 90, 328-334. 
Comita, L.S., Queenborough, S.A., Murphy, S.J., Eck, J.L., Xu, K., Krishnadas, M., Beckman, N., Zhu, Y., 2014. Testing predictions of the Janzen-Connell hypothesis: a meta-analysis of experimental evidence for distance- and density-dependent seed and seedling survival. J. Ecol. 102, 845-856.

Connell, J.H., 1971. On the role of natural enemies in preventing competitive exclusion in some marine animals and in rain forest trees, in: den Boer, P.J., Gradwell, G.R. (Eds.), Dynamics of Populations. PUDOC, Wageningen, pp. 298-312.

Crockford, R.H., Richardson, D.P., 2000. Partitioning of rainfall into throughfall, stemflow and interception: effect of forest type, ground cover and climate. Hydrol. Process. 14, 2903-2920.

Ellenberg, H., Weber, H., Düll, R., Wirth, V., Werner, W., Pauliben, D., 1992. Zeigerwerte von Pflanzen in Mitteleuropa. Scr. Geobot. 18, 1-248.

Gossner, M.M., Chao, A., Bailey, R.I., Prinzing, A., 2009. Native fauna on exotic trees: phylogenetic conservatism and geographic contingency in two lineages of phytophages on two lineages of trees. Am. Nat. 173, 599-614.

Hervé, M., 2015. RVAideMemoire: diverse basic statistical and graphical functions. R package version 0.9-45-2. http://CRAN.R-project.org/package=RVAideMemoire/ (accessed 30.10.15).

Humphrey, J.W., Swaine, M.D., 1997. Factors affecting the natural regeneration of Quercus in Scottish oakwoods. II. Insect defoliation of trees and seedlings. J. Appl. Ecol. 34, 585-593.

Hurvich, C.M., Tsai, C.L., 1989. Regression and time series model selection in small samples. Biometrika 76, 297-307.

Hyatt, L.A., Rosenberg, M.S., Howard, T.G., Bole, G., Fang, W., Anastasia, J., Brown, K., Grella, R., Hinman, K., Kurdziel, J.P., Gurevitch, J., 2003. The distance dependence prediction of the JanzenConnell hypothesis: a meta-analysis. Oikos 103, 590-602.

Jactel, H., Van Halder, I., Menassieu, P., Zhang, Q.H., Schlyter, F., 2001. Non-host volatiles disrupt the response of the stenographer bark beetle, Ips sexdentatus (Coleoptera: Scolytidae), to pheromonebaited traps and maritime pine logs. Integ. Pest Manag. Rev. 6, 197-207. 
Janzen, D.H., 1970. Herbivores and the number of tree species in tropical forests. Am. Nat. 104, 501528.

Lefcheck, J.S., 2016. piecewiseSEM: piecewise structural equation modelling in R for ecology, evolution, and systematics. Methods Ecol. Evol. 7, 573-579.

Legendre, P., Dale, M.R.T., Fortin, M.J., Casgrain, P., Gurevitch, J., 2004. Effects of spatial structures on the results of field experiments. Ecology 85, 3202-3214.

Liu, X., Liang, M., Etienne, R.S., Wang, Y., Staehelin, C., Yu, S., 2012. Experimental evidence for a phylogenetic Janzen-Connell effect in a subtropical forest. Ecol. Lett. 15, 111-118.

Masaki, T., Nakashizuka, T., 2002. Seedling demography of Swida controversa: effect of light and distance to conspecifics. Ecology 83, 3497-3507.

Moles, A.T., Westoby, M., 2004. What do seedlings die from and what are the implications for evolution of seed size? Oikos 106, 193-199.

Nakagawa, S., Schielzeth, H., 2013. A general and simple method for obtaining $R^{2}$ from generalized linear mixed-effects models. Methods Ecol. Evol. 4, 133-142.

Packer, A., Clay, K., 2000. Soil pathogens and spatial patterns of seedling mortality in a temperate tree. Nature 404, 278-281.

Packer, A., Clay, K., 2003. Soil pathogens and Prunus serotina seedling and sapling growth near conspecific trees. Ecology 84, 108-119.

Paine, C.E.T., Norden, N., Chave, J., Forget, P.M., Fortunel, C., Dexter, K.G., Baraloto, C., 2012. Phylogenetic density dependence and microenvironmental filtering predict seedling mortality in a tropical forest. Ecol. Lett. 15, 34-41.

Peters, H.A., 2003. Neighbour-regulated mortality: the influence of positive and negative density dependence on tree populations in species-rich tropical forests. Ecol. Lett. 6, 757-765. 
Pinheiro, J., Bates, D., DebRoy, S., Sarkar, D., the R core team, 2014. nlme: linear and nonlinear mixed effects models. R package version 3.1-117. http://CRAN.R-project.org/package=nlme/ (accessed 30.03.16).

R Core Team, 2014. R: A language and microenvironment for statistical computing. R Foundation for Statistical Computing, Vienna.

Rutten, G., Prati, D., Hemp, A., Fischer, M., 2016. Plant-soil feedback in East-African savanna trees. Ecology 97, 294-301.

Sariyildiz, T., Anderson, J.M., Kucuk, M., 2005. Effects of tree species and topography on soil chemistry, litter quality, and decomposition in Northeast Turkey. Soil Biol. Biochem. 37, 1695-1706.

Seiwa, K., 1998. Advantages of early germination for growth and survival of seedlings of Acer mono under different overstorey phenologies in deciduous broad-leaved forests. J. Ecol. 86, 219-228.

Seiwa, K., Miwa, Y., Sahashi, N., Kanno, H., Tomita, M., Ueno, N., Yamazaki, M., 2008. Pathogen attack and spatial patterns of juvenile mortality and growth in a temperate tree, Prunus grayana. Can. J. Forest Res. 38, 2445-2454.

Southwood, T.R.E., Wint, G.R.W., Kennedy, C.E.J., Greenwood, S.R., 2004. Seasonality, abundance, species richness and specificity of the phytophagous guild of insects on oak (Quercus) canopies. Eur. J. Entomol. 101, 43-50.

Taylor, K., Rowland, A.P., Jones, H.E., 2001. Molinia caerulea (L.) Moench. J. Ecol. 89, 126-144. Taylor, J.B., Wallace, B.D., 1970. Root canker in stone fruit caused by fungus Peniophora sacrata. Orchardist of New Zealand 43, 263-265.

Thomas, F.M., Blank, R., Hartmann, G., 2002. Abiotic and biotic factors and their interactions as causes of oak decline in Central Europe. Forest Pathol. 32, 277-307.

Wada, N., Murakami, M., Yoshida, K., 2000. Effects of herbivore-bearing adult trees of the oak Quercus crispula on the survival of their seedlings. Ecol. Res. 15, 219-227. 
Webb, C.O., Gilbert, G.S., Donoghue, M.J., 2006. Phylodiversity-dependent seedling mortality, size structure, and disease in a Bornean rain forest. Ecology 87, S123-S131.

Wills, C., Green, D.R., 1995. A genetic herd-immunity model for the maintenance of MHC polymorphism. Immunol. Rev. 143, 263-292.

Winkler, I.S., Mitter, C., 2008. The phylogenetic dimension of insect/plant interactions: a summary of recent evidence, in: Tilmon, K. (Ed.), Specialization, speciation, and radiation: the evolutionary biology of herbivorous insects. University of California Press, Berkeley, CA, pp. 240-263.

Wright, S.J., 2002. Plant diversity in tropical forests: a review of mechanisms of species coexistence. Oecologia 130, 1-14.

Yamamoto, S.I., 1992. The gap theory in forest dynamics. Bot. Mag. 105, 375-383.

Yguel, B., Bailey, R., Tosh, N.D., Vialatte, A., Vasseur, C., Vitrac, X., Jean, F., Prinzing, A., 2011. Phytophagy on phylogenetically isolated trees: why hosts should escape their relatives. Ecol. Lett. 14, $1117-1124$.

Zywiec, M., 2013. Seedling survival under conspecific and heterospecific trees: the initial stages of regeneration of Sorbus aucuparia, a temperate fleshy-fruited pioneer tree. Ann. Bot. Fenn. 50, 361371. 


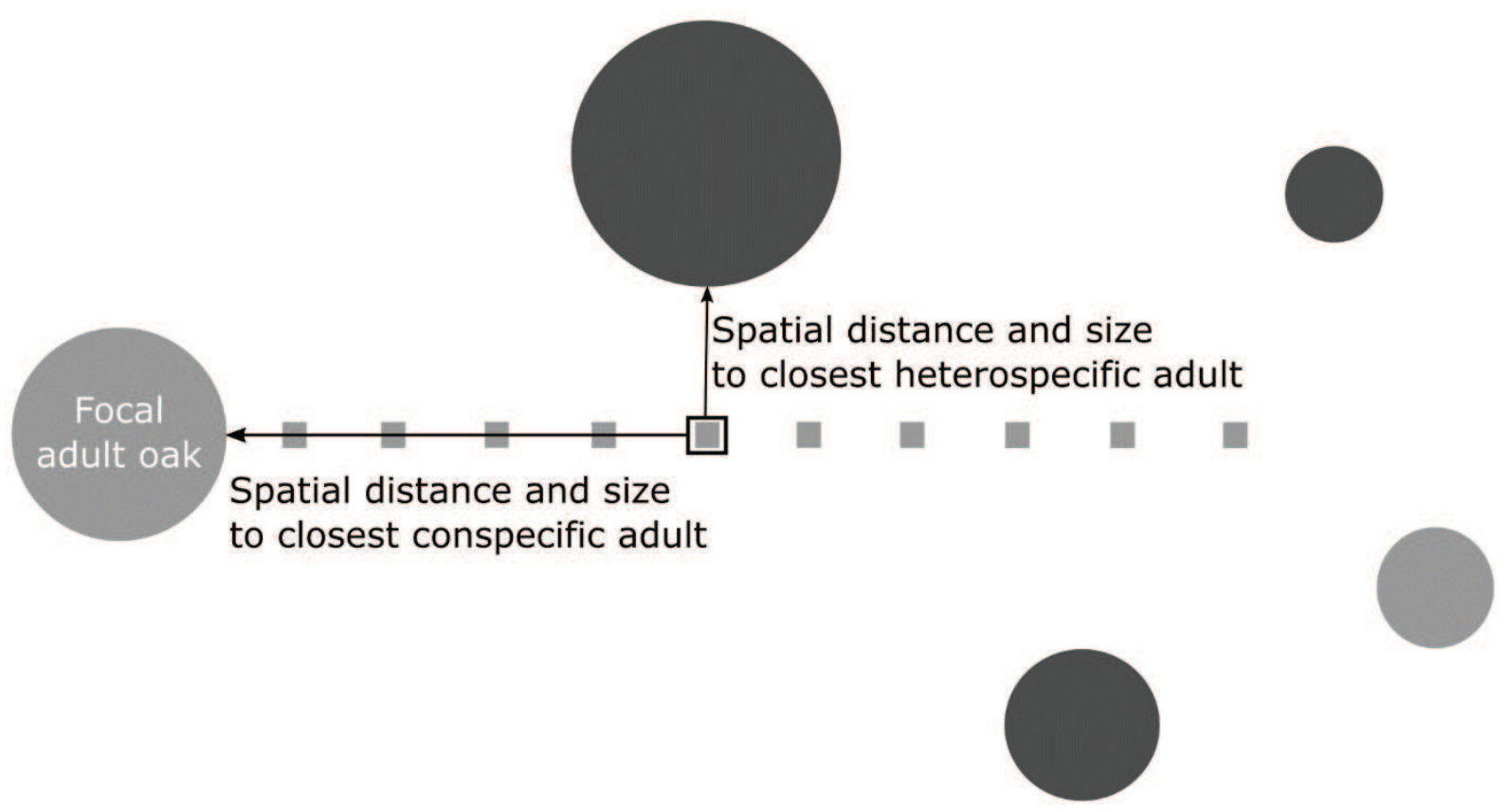

Fig. 1. Ten oak seedlings (grey squares) were transplanted every $0.5 \mathrm{~m}$ along a $5 \mathrm{~m}$ transect perpendicular to the stem of each focal adult oak tree. Light grey circles represent conspecific adults (i.e. oaks) and dark grey circles represent heterospecific adults. We measured the spatial distance between each seedling and the spatially closest conspecific adult (e.g. the focal adult oak for the enclosed seedling), also measuring the size of this conspecific adult; and the distance between each seedling and the spatially closest heterospecific adult (e.g. the upper heterospecific adult for the circled seedling), also measuring the size of this heterospecific adult. We also determined the evolutionary distance between each oak seedling and the spatially closest adult (e.g. the species of the upper heterospecific adult for the circled seedling). 


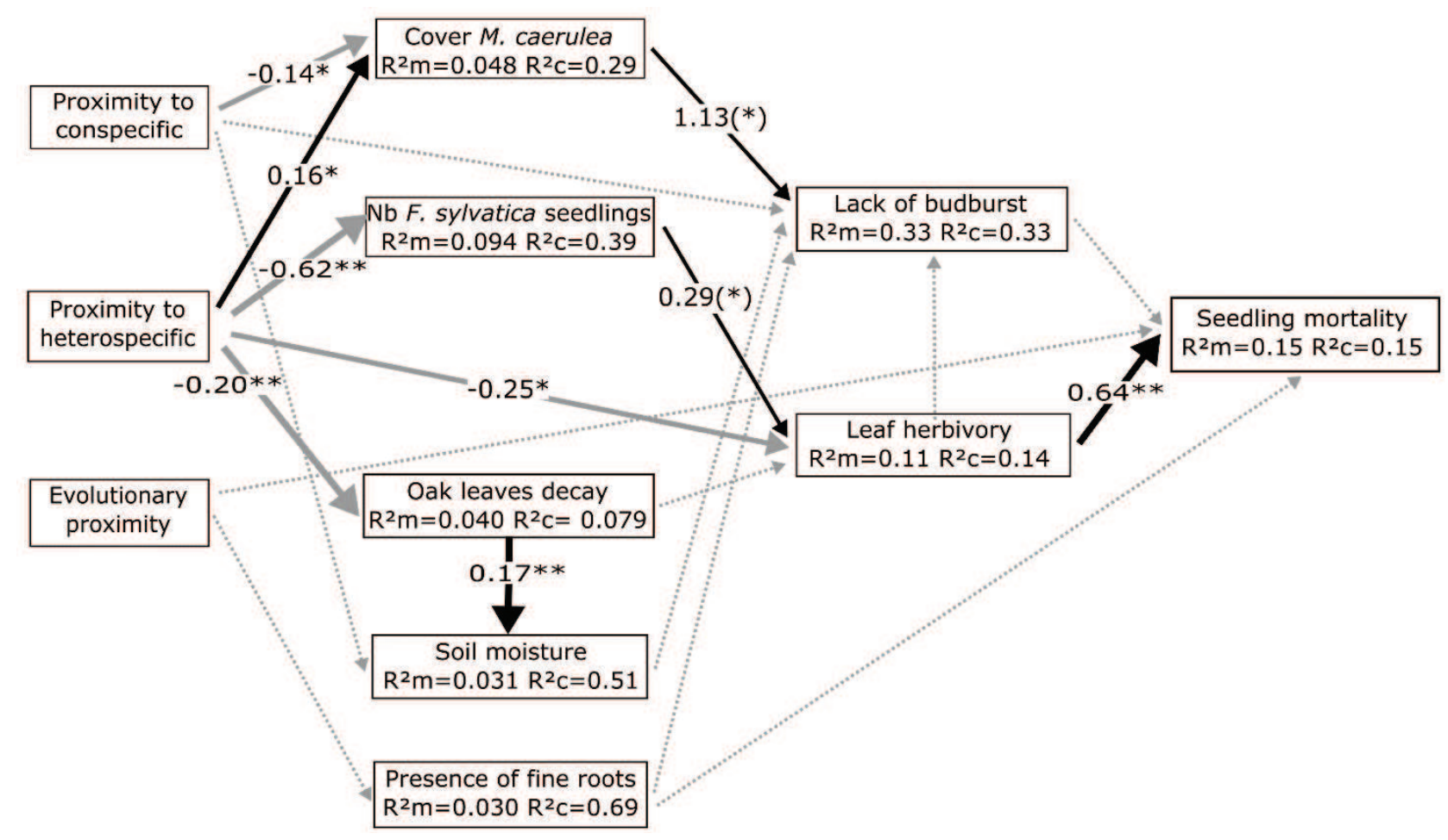

Fig. 2. Structural equation model representing effect of neighbouring adults on seedling mortality and processes controlling seedling mortality (lack of budburst, leaf herbivory), directly and through the microenvironment $(\mathrm{C}=55, \mathrm{P}=0.51, \mathrm{n}=97)$. 'Tree pair' was included as random factor in the analysis. Full black and grey arrows represent at least marginally significant $(\mathrm{P}<0.10)$ positive and negative relations respectively; and dotted arrows remaining relationships included into the model but not ranked significant $(\mathrm{P} \geq 0.1)$. Standardized coefficients are shown. Line width corresponds to the strength of the signal. (*) $\mathrm{P}<0.1,{ }^{*} \mathrm{P}<0.05,{ }^{*} \mathrm{P}<0.01,{ }^{*} * * \mathrm{P}<0.001$. See Appendix $\mathrm{E}$ for detailed results. 


\section{TABLE}

Table 1 Effect of neighbouring adults on seedling mortality, lack of budburst and leaf herbivory.

Mixed models were utilized, including 'tree pair' as random factor and its effect is not presented. The best model was selected after a best subset research based on the AICc. Bold values present statistical significance $\left((*) \mathrm{P}<0.1, * \mathrm{P}<0.05, * * \mathrm{P}<0.01,{ }^{* * *} \mathrm{P}<0.001\right)$. 'Full model' is the variance explained by a model without variable selection.

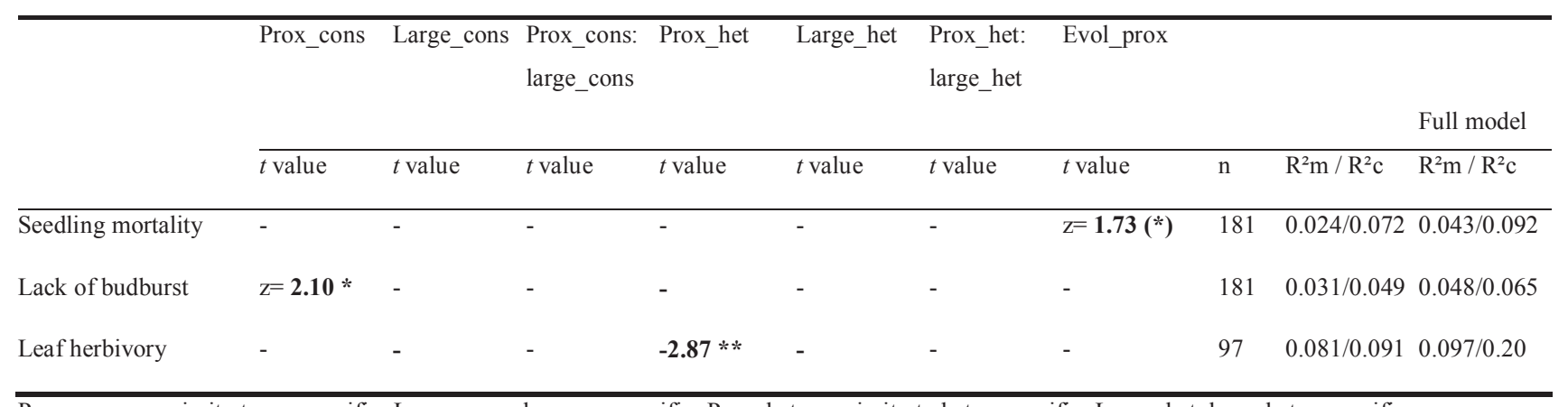

Prox_cons, proximity to conspecific; Large_cons, large conspecific; Prox_het, proximity to heterospecific; Large_het, large heterospecific;

Evol_prox, evolutionary proximity 
Table 2 Summary of detected relationships between adults and seedlings. Relationships like a JanzenConnell pattern are given in non-italic, opposite Janzen-Connell pattern in italic. Patterns resulting from the Janzen-Connell process are shaded grey, such resulting from alternative Janzen-Connell processes white, i.e. (1) heterospecific adults might positively affect seedlings; (2) conspecific adults might negatively affect seedlings by deteriorating the microenvironment.

\begin{tabular}{|c|c|c|}
\hline & Direct effect & Indirect effect via microenvironment \\
\hline Conspecific (or closely related) adult & $\begin{array}{l}\text { Expected effect on seedlings for a Janzen- } \\
\text { Connell-like pattern: } \\
\text { - }\end{array}$ & $\begin{array}{l}\text { Expected effect on seedlings for a Janzen- } \\
\text { Connell-like pattern: } \\
\text { - }\end{array}$ \\
\hline Proximity conspecific & - $\quad$ increased lack of budburst & $\begin{array}{l}+\quad \text { reduced lack of budburst } \\
\text { due to low } \mathrm{M} \text {. caerulea cover }\end{array}$ \\
\hline Closely related & increased mortality & \\
\hline \multicolumn{3}{|l|}{ Large conspecific } \\
\hline Heterospecific adult & $\begin{array}{l}\text { Expected effect on seedlings for a Janzen- } \\
\text { Connell-like pattern: } \\
+\end{array}$ & $\begin{array}{l}\text { Expected effect on seedlings for a Janzen- } \\
\text { Connell-like pattern: } \\
+\end{array}$ \\
\hline \multirow[t]{2}{*}{ Proximity heterospecific } & $\begin{array}{l}+ \\
\text { which reduced seedling mortality }\end{array}$ & $\begin{array}{l}+\quad \text { reduced leaf herbivory } \\
\text { due to low F. sylvatica density }\end{array}$ \\
\hline & & $\begin{array}{l}\text { - increased lack of budburst } \\
\text { due to high M. caerulea cover }\end{array}$ \\
\hline Large heterospecific & & \\
\hline
\end{tabular}

